\title{
Chromatographic Pattern of Glycated Hemoglobin Seen In a Patient Population at the Outpatient Clinic of a Nigerian Tertiary Hospital
}

\author{
${ }^{1}$ Ezeani IU, ${ }^{1}$ Nwabuko CO,${ }^{2}$ Nnoli MA, ${ }^{3}$ Chuku A, Onyia CC \\ ${ }^{I}$ Departments of Medicine and Hematology, Federal Medical Center, Umuahia, Abia State Nigeria. \\ ${ }^{2}$ Department of Anatomical Pathology, University of Calabar Teaching Hospital, Calabar. \\ ${ }^{3}$ Department of Ophthalmology, Federal Medical Center, Umuahia.
}

\begin{abstract}
Background: Glycated Hemoglobin ( $\left.H b A_{l c}\right)$ gives an estimate of long-term average glycaemic status. It is used routinely to assess glycaemic control in diabetics to attain treatment goals and prevent long term complications. The purpose of this study is to determine the Chromatographic pattern of Glycated hemoglobin seen in a patient population at the Federal Medical Center Umuahia using the D-10 High Performance Liquid Chromatography machine.

Methodology/Results: This is a descriptive study in which seventy consecutive patients attending the medical outpatient clinic of the Federal Medical Center, Umuahia were recruited. The study population comprises of 31 (44.3\%) males and 39 (44.3\%) females. All the study subjects were adults with majority of them (24.3\%) between the age group of 20-30 years. This study revealed that $4.3 \%$ of patients had $\mathrm{Hb} A_{1 c}$ values of less than $4 \%$ while $18.6 \%$ had high values of $8 \%$ and above. Majority of the patients (48.6\%) had HbA $A_{\text {Ic }}$ values between 4-6\%. Also $33.8 \%$ of the study population was known to have Type 2 DM while $66.2 \%$ were not known diabetic patients: $69.6 \%$ of diabetics had $\mathrm{Hb}_{1 c}$ values greater than $7 \%$. Majority of the patients not known to have diabetes had $H b A_{I c}$ values less than $7 \%$, however $11.1 \%$ of the patients who were not previously known to have diabetes had $\mathrm{HbA}_{\text {Ic }}$ levels greater than $7 \%$.

Conclusion: The $H b A_{l c}$ assay provides an accurate, precise measure of chronic glycaemic levels and in our environment, using $\mathrm{Hb}_{\text {Ic }}$ for the diagnosis of diabetes could increase the target population for preventive and therapeutic measures. The National Health Insurance policy should be strengthened and implemented in order to assist the poor and socially disadvantaged in getting adequate healthcare.
\end{abstract}

Key words: Glycated hemoglobin, Type 2 Diabetes Mellitus, D-10 Machine, High Performance Liquid Chromatography.

\section{Introduction:}

Glycated hemoglobin or glycosylated hemoglobin (hemoglobin $\mathrm{A} 1 \mathrm{C}, \mathrm{HbA}_{1 \mathrm{c}}, \mathrm{A} 1 \mathrm{C}$, or $\mathrm{Hb}_{1 \mathrm{c}}$; sometimes also $\mathrm{HbAlc}$ ) is a form of hemoglobin that is measured primarily to identify the average plasma glucose concentration over prolonged periods of time. ${ }^{1}$ Hemoglobin A1c was first separated from other forms of hemoglobin by Huisman and Meyering in 1958 using a chromatographic column. ${ }^{2}$ It was first characterized as a glycoprotein by Bookchin and Gallop in 1968. ${ }^{3}$ Its increase in diabetes was first described in 1969 by Samuel Rahbar et al. ${ }^{4}$ The reactions leading to its formation were characterized by Bunn and his coworkers in $1975 .{ }^{5}$ The use of hemoglobin Alc for monitoring the degree of control of glucose metabolism in diabetic patients was proposed in 1976 by Anthony Cerami, Ronald Koenig and coworkers. ${ }^{6}$ It is formed in a non-enzymatic glycation pathway by hemoglobin's exposure to plasma glucose. ${ }^{1}$ Normal levels of glucose produce a normal amount of glycated hemoglobin. As the average amount of plasma glucose increases, the fraction of glycated hemoglobin increases in a predictable way. This serve as a marker for average blood glucose levels over the previous months prior to the measurement. ${ }^{1}$

Ketoamine reactions between glucose and other sugars and free amino groups on the alpha and beta chain lead to glycated forms of hemoglobin. ${ }^{1}$ Only glycation of the N-terminal valine of the beta chain imparts sufficient negative charge to the hemoglobin molecule to allow separation by charge-dependent techniques. The charge-separated hemoglobin is collectively referred to as hemoglobin $\mathrm{A}_{1}\left(\mathrm{HbA}_{1}\right){ }^{1}$ The major form of $\mathrm{HbA}_{1}$ is hemoglobin $A_{1 c}\left(\mathrm{HbA}_{1 c}\right)$, where glucose is the carbohydrate. This form comprises 4-6\% of total hemoglobin. The remaining $\mathrm{HbA}_{1}$ species contain fructose 1,6-diphosphate $\left(\mathrm{HbA}_{1 \mathrm{a} 1}\right)$, glucose 6-phosphate $\left(\mathrm{HbA}_{1 \mathrm{a2}}\right)$, and an unknown carbohydrate moiety $\left(\mathrm{HbA}_{1 \mathrm{~b}}\right)$. The hemoglobin $\mathrm{A}_{1 \mathrm{C}}$ fraction is abnormally elevated in diabetic patients with chronic hyperglycemia. ${ }^{1}$ Some laboratories measure the sum of these glycohemoglobins (GHbs) and report the total as hemoglobin $\mathrm{A}_{1}$, but more laboratories are converting to the more intricate but highly specific $\mathrm{HbA}_{1 \mathrm{c}}$ assay. ${ }^{1}$ Methods for measuring $\mathrm{Hb}_{\mathrm{Alc}}$ include electrophoresis, cation exchange chromatography, boronate affinity chromatography, and immunoassays. Because GHbs circulate within red blood cells whose life span 
lasts up to 120 days, they generally reflect the state of glycemia over the preceding $8-12$ weeks, thereby providing an improved method of assessing diabetic control. ${ }^{1}$ The accuracy of $\mathrm{HbA}_{1 \mathrm{c}}$ values can be affected by hemoglobin variants or derivatives - the effect depending on the specific hemoglobin variant or derivative and the specific assay used.

Even though several studies on glycated hemoglobin has been done using other methods of assaying $\mathrm{HbA}_{1 \mathrm{c}}$, literature search has revealed that there has not been any study in the South-east geopolitical region of Nigeria on glycated hemoglobin using the D10 - HPLC platform machine hence the need for this study.

\subsection{Aims and Objectives:}

1. To determine the pattern of Glycated hemoglobin seen in a patient population at the Federal Medical Center Umuahia using the D-10 HPLC machine.

2. To use findings from this study to make appropriate recommendations that would improve on Glycated hemoglobin screening policies in other Health institutions in Nigeria.

\section{Methodology.}

This is a descriptive study carried out at the medical outpatient department of the Federal Medical Center (FMC), Umuahia, Abia state, a 1000 bed tertiary health facility located in the South-east geopolitical region of Nigeria. Federal Medical Center Umuahia receives referral from neighboring towns like Aba, IkotEkpene and all the local government areas within Abia state. It was a prospective study where consecutive patients who presented at the general outpatient clinic between March and May 2013 were recruited. Sociodemographic data was documented in a questionnaire, blood sample was collected and the chromatographic patterns of their Glycated Hbs were obtained using the D-10 ${ }^{\mathrm{TM}}$ Hbk HPLC Testing system (Bio-Rad laboratories). The American Diabetic Association (ADA) 2010 criteria were used in categorizing patients ${ }^{7}$. Statistical analysis was done using SPSS v 16.

2.1 Principle of the D-10 Test: HbAlc, the glycohemoglobin of interest, is formed in two steps by the nonenzymatic glycation of $\mathrm{HbA}$. The first step is the formation of an unstable aldimine (labile A1c, or pre-A1c), a reversible reaction between the carbonyl group of glucose and the $\mathrm{N}$ terminal valine of the $\beta$-chain of hemoglobin. ${ }^{8}$ Labile A1c formation is directly proportional to the blood glucose concentration. During red blood cell circulation, some of the labile Alc is converted (Amadori rearrangement) to form a stable ketoamine, HbA1c. ${ }^{9}$ The D-10 Hemoglobin Alc Program is based on chromatographic separation of HbAlc on a cation exchange cartridge. Separation is optimized to minimize interferences from hemoglobin variants, labile A1c, and carbamylated hemoglobin. ${ }^{8}$

The D-10 Hemoglobin A1c Program utilizes principles of ion-exchange high-performance liquid chromatography (HPLC). ${ }^{8}$ The samples are automatically diluted on the D-10 and injected into the analytical cartridge. The D-10 delivers a programmed buffer gradient of increasing ionic strength to the cartridge, where the hemoglobins are separated based on their ionic interactions with the cartridge material. ${ }^{8}$ The separated hemoglobins then pass through the flow cell of the filter photometer, where changes in the absorbance at 415 $\mathrm{nm}$ are measured. The software performs reduction of raw data collected from each analysis. Two-level calibration is used for quantitation of the HbAlc values. A sample report and chromatogram are generated for each sample. The A1c peak is shaded. This area is calculated using an exponentially modified Gaussian (EMG) algorithm that excludes the labile A1c and carbamylated peak areas from the A1c peak area. ${ }^{8}$

2.2 Sample collection: Whole blood specimens were collected, with standard venipuncture technique, in a $4 \mathrm{ml}$ vacuum collection tube containing EDTA (purple top tube). The samples were sent to the laboratory the same day of collection.

\section{Results}

3.1. Demographic distribution of the study population: A total of seventy (70) patients made up of 31 (44.3\%) males and $39(44.3 \%)$ females were seen within the study period. All the study subjects were adults with majority of them (24.3\%) between the age group of 20-30 years. Table 1 below shows the age and gender distribution of the study population. A total of three patients (4.3\%) were less than 20 years while four patients $(5.7 \%)$ were more than 70 years. 
Table 1: Age (years) and Gender distribution of Study population.

\begin{tabular}{|c|c|c|c|c|c|}
\hline \multicolumn{6}{|c|}{ Age in years } \\
\hline & & Frequency & Percent & Valid Percent & $\begin{array}{c}\text { Cumulative } \\
\text { Percent }\end{array}$ \\
\hline \multirow[t]{8}{*}{ Valid } & Under 20 years & 3 & 4.3 & 4.6 & 4.6 \\
\hline & $20-30$ years & 17 & 24.3 & 26.2 & 30.8 \\
\hline & $30-40$ years & 13 & 18.6 & 20.0 & 50.8 \\
\hline & $40-50$ years & 10 & 14.3 & 15.4 & 66.2 \\
\hline & $50-60$ years & 9 & 12.9 & 13.8 & 80.0 \\
\hline & $60-70$ years & 9 & 12.9 & 13.8 & 93.8 \\
\hline & Above 70 years & 4 & 5.7 & 6.2 & 100.0 \\
\hline & Total & 65 & 92.9 & 100.0 & \\
\hline Missing & System & 5 & 7.1 & & \\
\hline Total & & 70 & 100.0 & & \\
\hline
\end{tabular}

\begin{tabular}{|rl|r|r|r|r|}
\hline & & & & \multicolumn{1}{c|}{ Gender } \\
& & Frequency & Percent & Valid Percent & \multicolumn{1}{c|}{ Percent } \\
\hline Valid & Male & 31 & 44.3 & 44.3 & 44.3 \\
& Female & 39 & 55.7 & 55.7 & 100.0 \\
& Total & 70 & 100.0 & 100.0 & \\
\hline
\end{tabular}

3.2. Distribution of glycated hemoglobin: Three patients (4.3\%) had the lowest HbAlc values of $4 \%$ and below while thirteen patients $(18.6 \%)$ had the highest values of $8 \%$ and above. Majority of the patients $(48.6 \%)$ had $\mathrm{HbAlc}$ values between $4-6 \%$. This is shown in table 2 below.

Table 2. Shows the percentage distribution of the different range of HbA1c values

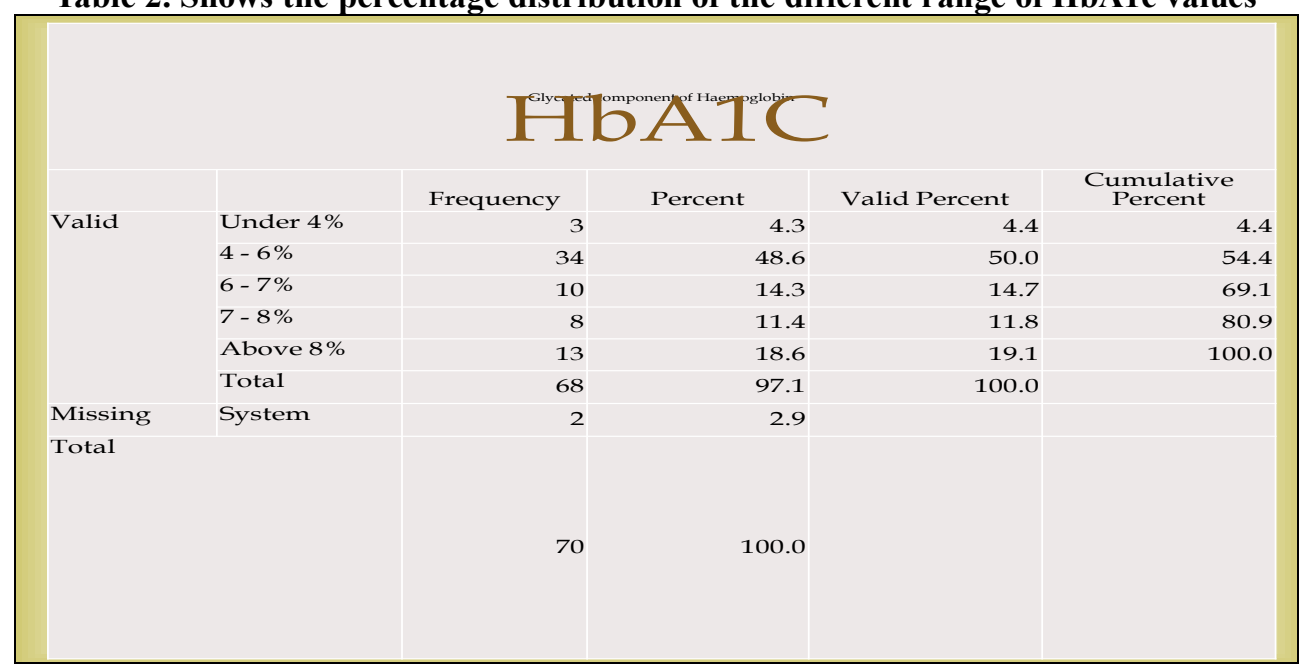

Table 3. Distribution of the population according to history of Type 2 Diabetes Mellitus

\begin{tabular}{|l|l|l|l|l|l|}
\hline $\mathbf{H b A}_{\mathbf{1 c}}$ value (\%) & Frequency & $\begin{array}{l}\text { Known DM } \\
\text { (percent) }\end{array}$ & $\begin{array}{l}\text { Known DM } \\
\text { (Valid percent) }\end{array}$ & $\begin{array}{l}\text { Not a known DM } \\
\text { (percent) }\end{array}$ & $\begin{array}{l}\text { Not a known DM } \\
\text { (Valid percent) }\end{array}$ \\
\hline$<4$ & 3 & $0(0.0)$ & 0.0 & $3(60.0)$ & 100.0 \\
\hline $4-6$ & 34 & $3(8.3)$ & 8.8 & $31(86.1)$ & 91.2 \\
\hline $6-7$ & 10 & $4(33.3)$ & 40.0 & $6(50.0)$ & 60.0 \\
\hline $7-8$ & 8 & $6(60.0)$ & 75.0 & $2(20.0)$ & 25.0 \\
\hline$>8$ & 13 & $10(66.7)$ & 76.9 & $3(20.0)$ & 66.2 \\
\hline Total & 68 & $23(32.9)$ & 33.8 & $45(64.3)$ & \\
\hline Missing system & 2 & $(2.8)$ & & & \\
\hline Total & 70 & 100.0 &
\end{tabular}


Table 3 above shows the distribution of the study population according to the history of Type 2 Diabetes Mellitus.

\section{Discussion:}

HbA1c is the most widely used index to monitor glycaemic control during a period of approximately three months and strongly correlates with the mean blood glucose level. The Diabetes Control and Complications trial (DCCT) and the United Kingdom Prospective Diabetes Study (UKPDS) were large trials that demonstrated that $\mathrm{HbA}_{1 \mathrm{c}}$ levels are directly related to the risk of complications of diabetes, stroke and ischaemic heart disease. ${ }^{10,11} \mathrm{As}_{\mathrm{HbA}}$ ic also a strong predictor of new onset diabetes mellitus, the American Diabetes Association now recommends this test in the diagnosis of diabetes mellitus and for identifying prediabetes $^{7}$. The American College of Endocrinology (ACE) and American Association of Clinical Endocrinologists (AACE) perceive that $\mathrm{HbA}_{1 \mathrm{c}}$ should not be the primary criterion for the diagnosis of diabetes mellitus and that it should be used in conjunction with fasting plasma glucose and/or oral glucose tolerance tests. ${ }^{12}$ The International Diabetes Federation and American College of Endocrinology recommend $\mathrm{HbA}_{1 \mathrm{c}}$ values below $48 \mathrm{mmol} / \mathrm{mol}$ (6.5\%), while American Diabetes Association recommends that the $\mathrm{HbA}_{1 \mathrm{c}}$ be below $53 \mathrm{mmol} / \mathrm{mol}(7.0 \%)$ for most patients. ${ }^{13}$

Twenty three $(33.8 \%)$ of the study population were known to have Type 2 DM while $45(66.2 \%)$ of these patients were not known diabetic patients. Sixteen $(69.6 \%)$ of the twenty-three patients with diabetes had $\mathrm{HbA}_{1 \mathrm{c}}$ values greater than $7 \%$ indicating poor glycaemic control while seven had $\mathrm{HbA}_{1 \mathrm{c}}$ values less than $7 \%$ which indicates optimal glycaemic control. This is similar to the prevalence of $75 \%$ reported by Hasimah et $\mathrm{al}^{14}$ in a study done in Malaysia to access the control of $\mathrm{HbA}_{1 \mathrm{c}}$ among Type 2 diabetes mellitus patients attending an urban health clinic. A lower prevalence of $40.7 \%$ was reported by Miyar Otero et al ${ }^{15}$ in Sao Paolo, Brazil in a study on the socio-demographic and clinical characteristics of a diabetic population at a primary level health care center. D'souza et $\mathrm{al}^{16}$ in Oman reported that $50 \%$ of all diabetics in their study had $\mathrm{HbA}_{1 \mathrm{c}}$ value of more than $7 \%$. This clearly shows that there is preponderance of poor glycaemic control among known diabetic patients. In this study, majority of the patients (88.9\%) not known to have diabetes had $\mathrm{HbA}_{1 \mathrm{c}}$ values less than $7 \%$, however five $(11.1 \%)$ of the patients who were not previously known to have diabetes had $\mathrm{HbA}_{1 \mathrm{c}}$ levels greater than $7 \%$. This is higher than the value of 3\% reported by Bernal-Lopez et $\mathrm{al}^{17}$ in Southern Europe.

\section{Conclusion:}

This study revealed that $69.6 \%$ of the type 2 diabetes mellitus patients attending the medical outpatient clinic had poor diabetic control while $11.1 \%$ of the patients who were not previously known to have diabetes had elevated $\mathrm{HbA}_{1 \mathrm{c}}$ levels. Thus, more thought should be given to the importance of multi professional team education in diabetic patient care, with a view to: intensifying the strategies to obtain good glycaemic control; establishing a permanent means of communication between institutional health professionals and users, especially in the initial/adjustment phase of the diabetes treatment; reviewing the criteria established by health institutions regarding return visits, especially in the initial/adjustment phase of the diabetes treatment; involving the family and/or significant relatives in the education program, turning them into a collaborator in diabetic user care; and, finally, developing intervention research with diabetic users that encourage changes in habits and lifestyles, and permitting to understand what factors interfere and/or facilitate the achievement. The National Health Insurance policy should be strengthened and implemented in order to assist the poor and socially disadvantaged in getting adequate healthcare.

Limitations: Many factors that can influence $\mathrm{HbA}_{1 \mathrm{c}}$ levels (e.g. co-morbid conditions, physical activity index, genetically inherited hemoglobinopathies, income, marital status, employment, health literacy, social support system) have not been studied.

\section{References}

[1]. Umesh M, German MS. Pancreatic Hormones and Diabetes Mellitus; Glycated Hemoglobin Assays in: David GG, Dolores S (Eds). Greenspan's Basic and Clinical Endocrinology $8^{\text {th }}$ Edi. Appleton Lange: an imprint of McGraw-Hill Inc. 2007. 18: 685.

[2]. Huisman TH, Martis EA, Dozy A. Chromatography of hemoglobin types on carboxymethyl cellulose.J. Lab. Clin. Med. 1958: 52 (2): $312-27$.

[3]. Bookchin RM, Gallop PM. Structure of hemoglobin A1c: nature of the N-terminal beta chain blocking group. Biochem. Biophys. Res. Commun. 1968: 32 (1): 86-93.

[4]. Rahbar S, Blumenfeld O, Ranney HM. Studies of unusual Hemoglobin in patients with Diabetes Mellitus. Biochem. Biophys. Res. Commun. 1969: 36 (5): 838-43.

[5]. Bunn HF, Haney DN, Gabbay KH, Gallop PM. Further identification of the nature and linkage of the carbohydrate in hemoglobin A1c. Biochem. Biophys. Res. Commun. 1975: 67 (1): 103-9.

[6]. Koenig RJ, Peterson CM, Jones RL, Saudek C, Lehrman M, Cerami A. Correlation of glucose regulation and hemoglobin AIc in diabetes mellitus. N. Engl. J. Med. 1976: 295 (8): 417-20.

[7]. American Diabetes Association Clinical Practice Recommendations. Executive summary: standards of medical care in diabetes. Diabetes Care; 2010: 33 (1): 4-5. 
[8]. The D-10 ${ }^{\mathrm{TM}}$ Hemoglobin A1c Program Instruction Manual. United States, Bio-Rad Laboratories, Inc., Hercules, CA 94547: 2010: 2 .

[9]. Mayer, T. K.; Freedman, Z. R. Protein Glycosylation in Diabetes Mellitus: A Review of Laboratory Measurements and of Their Clinical Utility. Clin. Chim. Acta1; 1983: 127: 147-184.

[10]. The DCCT Research Group. The effect of intensive treatment of diabetes on the development and progression of long term complications in insulin-dependent diabetes mellitus. N. Engl J. Med; 1993: 329: 977-86.

[11]. UK Prospective Diabetes Study Group. Intensive blood glucose with sulphonylureas or insulin compared with conventional treatment and risk of complications in patients with Type 2 Diabetes. Lancet; 1998: 352: 837-53.

[12]. Rodbard HW, Jellinger PS, Davidson JA, et al. Statement by the American Association of Clinical Endocrinologists/ American College of Endocrinology Consensus Panel on Type 2 Diabetes Mellitus: an algorithm for glycemic control. Endocr Pract; 2009: 15(6): 540-59.

[13]. Executive Summary: Standards of medical care in diabetes. Diabetes Care. 2009: 32: 6-12.

[14]. Hasimah I, Muhamad H, Siti S, Salmiah MS, Tahir A, Hudaz MY. Medical and Health Sci Journal. 2011: 1804-1884: 9; 58-65.

[15]. Miyar Otero L, Zanetti ML, Teixeira CRS. Socio demographic and clinical characteristics of a diabetic population at a primary level health care center. Rev Latino-am Enfermagem. Setembro-outubro; 15(número especial): 2007: 768-73.

[16]. D'souza MS, Venkatesaperumal R, Karkada SN, Amirtharaj A. Determinants of Glycosylated Haemaglobin among Adults with Type 2 Diabetes Mellitus. J Diabetes Metab; 2013: 4: 265.

[17]. Bernal-Lopez MR, Santamaría FS, Lopez CD, Tinahones FJ, Mancera RJ, Peña JD, et al. HbA1c in adults without known diabetes from southern Europe. Impact of the new diagnostic criteria in clinical practice. Diabet Met; 2011: 28 (11):1319-22. 